
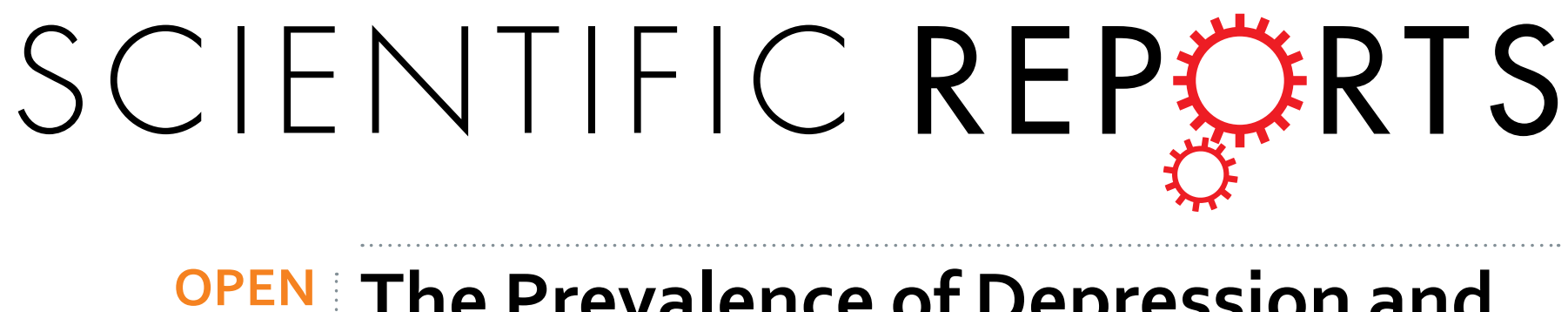

\title{
The Prevalence of Depression and Depressive Symptoms among Eye Disease Patients: A Systematic
}

Received: 23 June 2016

Accepted: 20 March 2017

Published: 12 April 2017

\section{Review and Meta-analysis}

\author{
Yajing Zheng*, Xiaohang Wu*, Xiaoming Lin \& Haotian Lin
}

The prevalence of depression among different eye disease patients varies across studies and has not been systematically reviewed. This study is to provide a summary of the prevalence of depression among eye disease patients. PubMed, Medline, Embase and Cochrane Library were searched from January, 1990 to December, 2015 to identify studies with information on the prevalence of depression among ophthalmic patients. A random/fixed-effects meta-analysis was used to estimate the pooled prevalence of depression among eye disease patients. Heterogeneity was assessed with the $I^{2}$ test. 28 studies were selected from 3162 references. The overall pooled prevalence of depression or depressive symptoms with eye disease was $25 \%$ ( $1502 / 6589$ individuals, $95 \% \mathrm{Cl}, 0.20-0.30)$ ranging from $5.4 \%$ to $57.0 \%$. Regarding different disease categories, the highest prevalence was revealed for dry eye disease (DED) with $29 \%$, followed by $25 \%$ for glaucoma patients, $24 \%$ for age-related macular degeneration (AMD) patients, $23 \%$ for cataract patients. The increased pooled prevalence of depression was identified in those with eye diseases compared with healthy controls $\left(O R, 1.59 ; 95 \% \mathrm{Cl}, 1.40-1.81 ; I^{2}=68.5 \%\right)$. Substantial heterogeneity was identified across most estimates $\left(I^{2}>75 \%\right)$. Further research is needed to identify effective strategies for preventing and treating depression among eye disease patients.

With the transformation from the biomedical to socio-psycho-biological medical model, an increasing attention has been paid on mental health and life quality during disease managements ${ }^{1}$. According to the epidemiological data from World Health Organization (WHO), the prevalence of depression occupies the fourth leading contributor to the global disease burden ${ }^{2}$ and is expected to increase ${ }^{3}$. Depression or depressive symptoms have been proved to be associated with various systemic diseases, including obesity ${ }^{4}$, metabolic disorders ${ }^{5}$ and cardiovascular diseases ${ }^{6}$, contributing to economic burden and social disturbance ${ }^{3}$.

Many studies have paid attention to psychological problems and suggest that mood disorders, particularly depression, are associated with eye disease $\mathrm{e}^{7-9}$. The progressive vision loss caused by age-related macular degeneration $(\mathrm{AMD})^{7}$, cataract ${ }^{10}$ or glaucoma ${ }^{11}$ constitutes a major source of disability; the chronic ocular discomforts induced by dry eye disease (DED) ${ }^{12}$ or inflammatory disorders ${ }^{8}$ may be related to the deteriorating mode status as well. Timely and effectively detection of the psychological changes will contribute to management of ocular symptoms, improvement of life quality, and also, maintaining peaceful communications between physicians and patients.

However, to our best knowledge, the prevalence of depression among various ophthalmic patients varies across studies ${ }^{7,8,10-35}$ and has not been systemically reviewed. The lowest reported prevalence of depression among eye disease patients is $5.4 \%{ }^{14}$, while the highest is $57 \%{ }^{26}$. Therefore, a systematic review and meta-analysis was performed to estimate the prevalence of depression among different eye disease patients.

\section{Results}

Study characteristics. Twenty-eight studies ${ }^{7,8,10-35}$ were finally included in the quantitative synthesis from 3162 original records (Fig. 1). Ten took place in America, 8 in Asia, 7 in Europe (including 1 multicenter study

State Key Laboratory of Ophthalmology, Zhongshan Ophthalmic Center, Sun Yat-sen University, Guangzhou, Guangdong, 510060, People's Republic of China. *These authors contributed equally to this work. Correspondence and requests for materials should be addressed toX.L. (email: linxiaom@mail.sysu.edu.cn) or H.L. (email: haot.lin@ hotmail.com) 


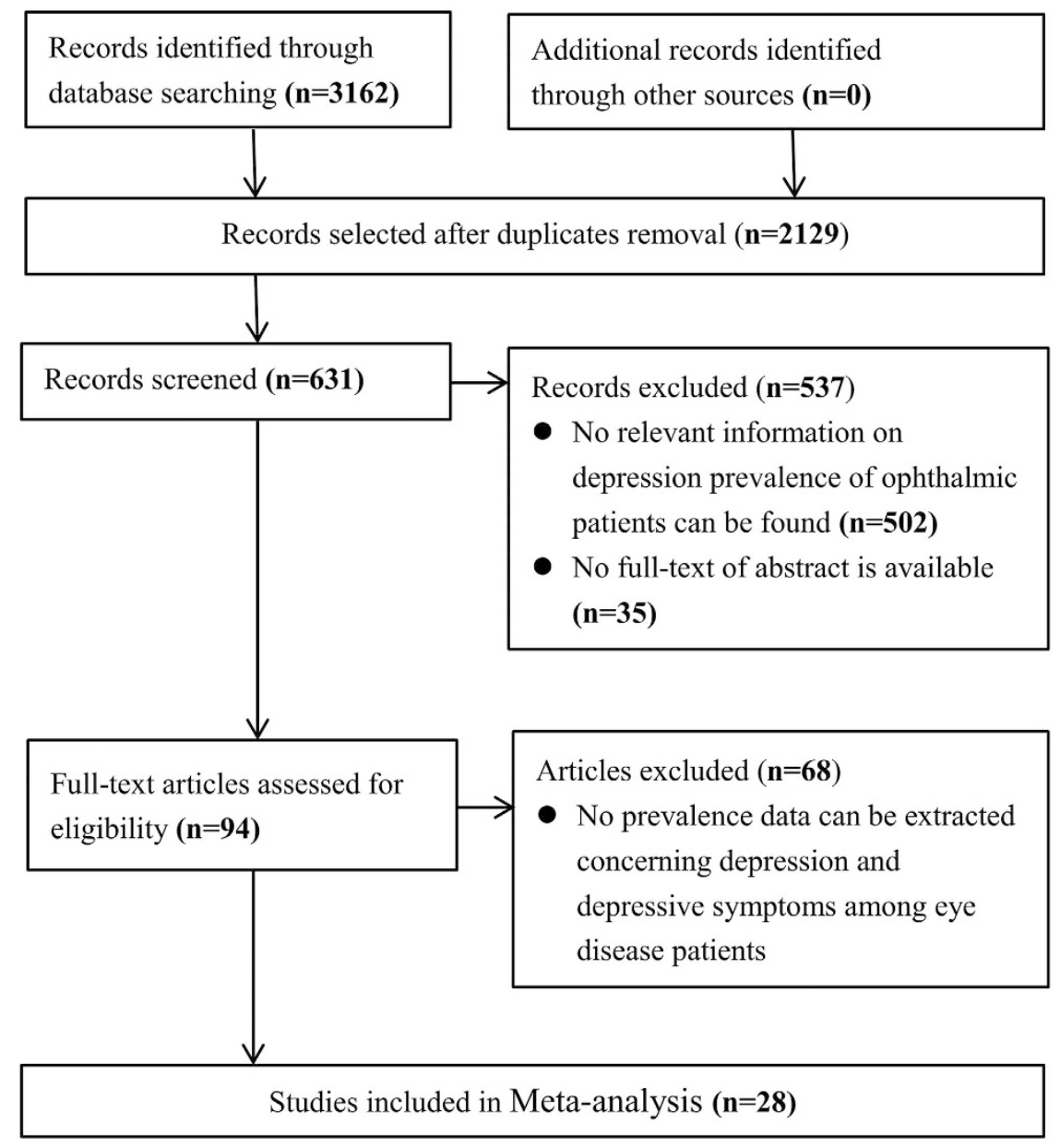

Figure 1. Flowchart of study selection process.

performed across France, Germany and Italy) and 3 in Australia. Eight studies focused on AMD, 5 on DED, 3 on cataract, 12 on glaucoma, and 4 on other eye diseases. Six studies assessed depression using the Hospital Anxiety and Depression Scale (HADS) ${ }^{36,37}, 3$ used the Center for Epidemiologic Studies Depression Scale (CES-D) ${ }^{38}, 6$ used the Geriatric Depression Scale (GDS $)^{39,40}, 4$ used the Beck Depression Inventory (BDI) ${ }^{41}, 1$ used the 9-items Patients Health Questionnaire (PHQ-9) ${ }^{42,43}, 1$ used the Goldberg Anxiety and Depression Scale (GADS) ${ }^{44}, 2$ used the Zung Self-rating Depression Scale (SDS $)^{45,46}, 1$ reported no questionnaire, and 4 used other assessed instruments ${ }^{47}$. Regarding quality assessment, 67.9\% (19/28) included studies received 3 points of higher, indicating low risk of bias. The prevalence of depression or depressive symptoms among eye disease patients ranged from $5.4 \%{ }^{14}$ to $57.0 \%^{11,26}$ in the systematic review and meta-analysis (Table 1 ).

Prevalence of depression among eye disease patients. The overall pooled prevalence of depression or depressive symptoms with eye diseases was 25\% (1502/6589 individuals, 95\% CI, 0.20-0.30) (Fig. 2). Regarding different eye disease subgroups, the highest depression prevalence was revealed for DED patients $29 \%$ (95\% CI, $0.17-0.40$ ), followed by $25 \%$ (95\% CI, $0.18-0.32$ ) for glaucoma patients, $24 \%$ (95\% CI, $0.18-0.30$ ) for AMD patients, 23\% (95\% CI, 0.07-0.40) for cataract patients, see Fig. 3. Substantial heterogeneity was identified across most estimates ( $\left.\mathrm{I}^{2}>75 \%\right)$ (Fig. 3 ).

Secondary analysis of $\mathbf{1}^{2}$ studies with control groups. The 13 of the 28 studies with control groups were included in the meta-analysis. The overall number of eye disease patients with depression or depressive symptoms was 574 (total of 3149), while it was 1092 (total of 12152) in the control group. The odds ratio of the meta-analysis depending on the random-effects model was $1.59\left(95 \% \mathrm{CI} 1.40-1.81, \mathrm{Q}=38.11, \mathrm{I}^{2}=68.5 \%\right)$. The forest plot revealed that the prevalence of depression of the control group was lower than that for the group with eye disease, and this difference was significant difference (Fig. 4). The funnel plot of the 13 studies with control groups was generally symmetrical (Supplementary Figure S1). The results of the Begg's test $(p=0.059)$ revealed no significant publication bias.

\section{Discussion}

This systematic review and meta-analysis demonstrated that the prevalence of depression among eye disease patients was 25\% (1502/6589 individuals, 95\% CI, 0.20-0.30), ranging from 5.4\% to 57\%. Regarding different 


\begin{tabular}{|c|c|c|c|c|c|c|c|c|}
\hline Study & Country & Disease & Age, $y$ & Study Design & Diagnostic Method & Outcome & $\begin{array}{l}\text { Depression Prevalence } \\
\text { (case/participant) }\end{array}$ & Nos \\
\hline Kong, $\mathrm{X} .{ }^{11}$ & China & Glaucoma & Mean (SD) $55.5(\mathrm{NR})$ & Cross-sectional study & SDS & $\geq 50$ & $48 \%(48 / 100)$ & 2 \\
\hline Hallak, J. A. ${ }^{13}$ & US & DED & Mean (SD) $52.6(16.2)$ & Cross-sectional study & BDI & $>9$ & $38 \%(19 / 50)$ & 3 \\
\hline Van der Aa, H. P. ${ }^{14}$ & Netherland & Eye disease & Mean (SD) $77.6(9.3)$ & Cross-sectional study & CES-D & $\geq 16$ & $5 \%(33 / 615)$ & 3 \\
\hline Ayaki, M. ${ }^{10}$ & Japan & Eye disease & Mean (SD) 59.5 (19.9) & Descriptive study & HADS & $\geq 10$ & $45 \%(332 / 730)$ & 3 \\
\hline Vehof J. ${ }^{34}$ & British & DED & Mean (SD) 57.1 (13.1) & $\begin{array}{c}\text { Cross-sectional study } \\
\text { (population-based) }\end{array}$ & Clinical diagnosis & NR & $17 \%(64 / 367)$ & 3 \\
\hline Labbé $\mathrm{A}^{35}$ & China & DED & Mean (SD) $67.3(9.6)$ & $\begin{array}{c}\text { Cross-sectional study } \\
\text { (population-based) }\end{array}$ & SDS & $\geq 40$ & $14 \%(33 / 241)$ & 3 \\
\hline Eramudugolla, R. ${ }^{15}$ & Australia & $\begin{array}{l}\text { Age-related eye } \\
\text { disease }\end{array}$ & Mean (range) NR $(>70)$ & $\begin{array}{c}\text { Cross-sectional study } \\
\text { (population-based) }\end{array}$ & GADS & NR & $7 \%(20 / 287)$ & 1 \\
\hline Agorastos, A. ${ }^{16}$ & Germany & Glaucoma & Mean (range) NR (>50) & Descriptive study & BDI-II & $\geq 10$ & $36 \%(31 / 86)$ & 3 \\
\hline Jivraj,.$^{17}$ & Canada & AMD & Mean (range) NR $(>50)$ & Descriptive study & CES-D & $\geq 16$ & $21 \%(20 / 94)$ & 4 \\
\hline Richards, H. S. ${ }^{18}$ & UK & Ptosis & Mean (SD) 61.6 (15.3) & Descriptive study & HADS & $>10$ & $11 \%(6 / 57)$ & 2 \\
\hline Kim, S. ${ }^{19}$ & Korea & $\mathrm{RP}$ & Mean (SD) 40.1 (11.0) & $\begin{array}{c}\text { Cross-sectional study } \\
\text { (population-based) }\end{array}$ & $\mathrm{NR}$ & NR & $35 \%(65 / 187)$ & 1 \\
\hline Lee, W. J. ${ }^{20}$ & Korea & AMD & Mean (SD) 55 (NR) & Descriptive study & GDS & $\geq 5$ & $26 \%(28 / 107)$ & 3 \\
\hline Zhou, C. ${ }^{21}$ & China & Glaucoma & Mean (SD) 55.4 (15.3) & Descriptive study & HADS & $>10$ & $16 \%(83 / 506)$ & 3 \\
\hline Qian, $\mathrm{Y}^{8}$ & US & Ocular inflammation & Mean (range) NR (>18) & Descriptive study & BDI & $>13$ & $27 \%(28 / 104)$ & 2 \\
\hline Popescu, M. L.22 & Canada & Eye disease & Mean (range) NR (>65) & Cross-sectional study & GDS-15 & $\geq 5$ & $31 \%(71 / 227)$ & 4 \\
\hline Yochim, B. P. ${ }^{23}$ & US & Glaucoma & Mean (SD) 70 (9.2) & Descriptive study & GDS & $\geq 5$ & $12 \%(5 / 41)$ & 3 \\
\hline Wang, S. Y. ${ }^{24}$ & US & Glaucoma & Mean (SD) $66.9(1.03)$ & $\begin{array}{c}\text { Cross-sectional study } \\
\text { (population-based) }\end{array}$ & PHQ-9 & $\geq 10$ & $11 \%(49 / 453)$ & 4 \\
\hline Kim, K. W. ${ }^{12}$ & Korea & DED & Mean (SD) $71.9(5.8)$ & $\begin{array}{c}\text { Cross-sectional study } \\
\text { (population-based) }\end{array}$ & SGDS-K & NR & $33 \%(66 / 198)$ & 1 \\
\hline Amaro, T. A. ${ }^{25}$ & US & Uveal melanoma & Mean (range) $52(29-80)$ & Descriptive study & BDI & $>11$ & $45 \%(9 / 20)$ & 3 \\
\hline Tastan, S. ${ }^{26}$ & Turkey & Glaucoma & Mean (SD) 64.2 (13.2) & Cross-sectional study & HADS & $\geq 8$ & $57 \%(69 / 121)$ & 4 \\
\hline Freeman, E. E. ${ }^{27}$ & Canada & Cataract & Mean (range) NR ( $>45)$ & Descriptive study & GDS-30 & $\geq 10$ & $26 \%(174 / 657)$ & 2 \\
\hline Banerjee, A. ${ }^{28}$ & US & AMD & Mean (range) NR $(>50)$ & Descriptive study & GDS & $>4$ & $26 \%(14 / 53)$ & 3 \\
\hline Mabuchi, $\mathrm{F}^{29}$ & Japan & Glaucoma & Mean (SD) $66.9(12.1)$ & Cross-sectional study & HADS & $>10$ & $11 \%(25 / 230)$ & 3 \\
\hline Skalicky, S. ${ }^{30}$ & Australia & Glaucoma & Mean (range) NR (70-90) & Descriptive study & GDS-15 & $>4$ & $19 \%(25 / 131)$ & 3 \\
\hline Augustin, A. ${ }^{7}$ & $\begin{array}{c}\text { France } \\
\text { Germany } \\
\text { Italy }\end{array}$ & AMD & Mean (SD) 77 (NR) & Descriptive study & HADS & $\geq 11$ & $18 \%(60 / 336)$ & 4 \\
\hline Sun, C. ${ }^{31}$ & Australia & AMD & Mean (range) NR (69-97) & Cross-sectional study & CES-D & $\geq 10$ & $16 \%(58 / 367)$ & 3 \\
\hline Cumurcu, $\mathrm{T}^{32}$ & Turkey & Glaucoma & Mean (range) NR (30-80) & Cross-sectional study & HDRS & NR & $25 \%(18 / 73)$ & 4 \\
\hline Brody, B. L. ${ }^{33}$ & US & AMD & Mean (SD) 80 (NR) & Descriptive study & DSM & $\begin{array}{c}\text { DSM-IV } \\
\text { criteria }\end{array}$ & $32 \%(49 / 151)$ & 1 \\
\hline Total & 1 & 1 & 1 & & 1 & 1 & $25 \%(1502 / 6589)$ & 1 \\
\hline
\end{tabular}

Table 1. Characteristics of 28 included studies in the systematic review and meta-analysis. NR $=$ Not related; Abbreviations: AMD, Age-related Macular Degeneration; DED, Dry Eye Disease; RP, Retinitis Pigmentosa; SDS, Self-Rating Depression Scale; HADS, Hospital Anxiety and Depression Scale; BDI, Beck Depression Inventory; CES-D, Center for Epidemiologic Studies Depression Scale; DSM, Diagnostic and Statistical Manual of Mental Disorders (Forth Edition);HADS, Hospital Anxiety and Depression Scale; NOS, Newcastle-Ottawa Score; NR, not reported; PHQ-9,9-item Patient Health Questionnaire; GDS, Geriatric Depression Scale; SGDS-K, the Korean version of Short Geriatric Depression Scale; SDS, Self-rating Depression Scale; GADS, Goldberg Anxiety and Depression Scale; HDRS, Hamilton Depression Rating Scale.

disease categories, the highest prevalence was revealed for DED with $29 \%$, followed by $25 \%$ for glaucoma patients, $24 \%$ for AMD patients, $23 \%$ for cataract patients. More than two thirds of included studies were assessed with low risk of bias, whereas, substantial heterogeneity was identified across most estimates. Depression or depressive symptoms in eye patients may be caused by a series of eye symptoms, which have a great impact on patients' daily lives, such as eye discomfort, foreign body sensation, pain, visual impairment and other symptoms ${ }^{10,35}$. This result may also be caused by social factors, doctor visits and medical expenses. The depressive symptoms of eye disease patients deserve more attention ${ }^{48,49}$.

Depressive symptoms may not only aggravate symptoms of eye disease but also affect other psychological systems ${ }^{50}$. For example, these patients usually felt sad, pessimistic and experienced cognitive disorders and pain, forming a vicious circle. With a change of the medical model, people are placing an increasing emphasis on the mental health of patients. It is imperative that social measures be introduced to improve health. These findings highlight an important social health issue in eye disease patients. In recent years, there have been numerous cases of violence against healthcare workers. The identification of patient mental health, including depression symptom 


\section{Study}

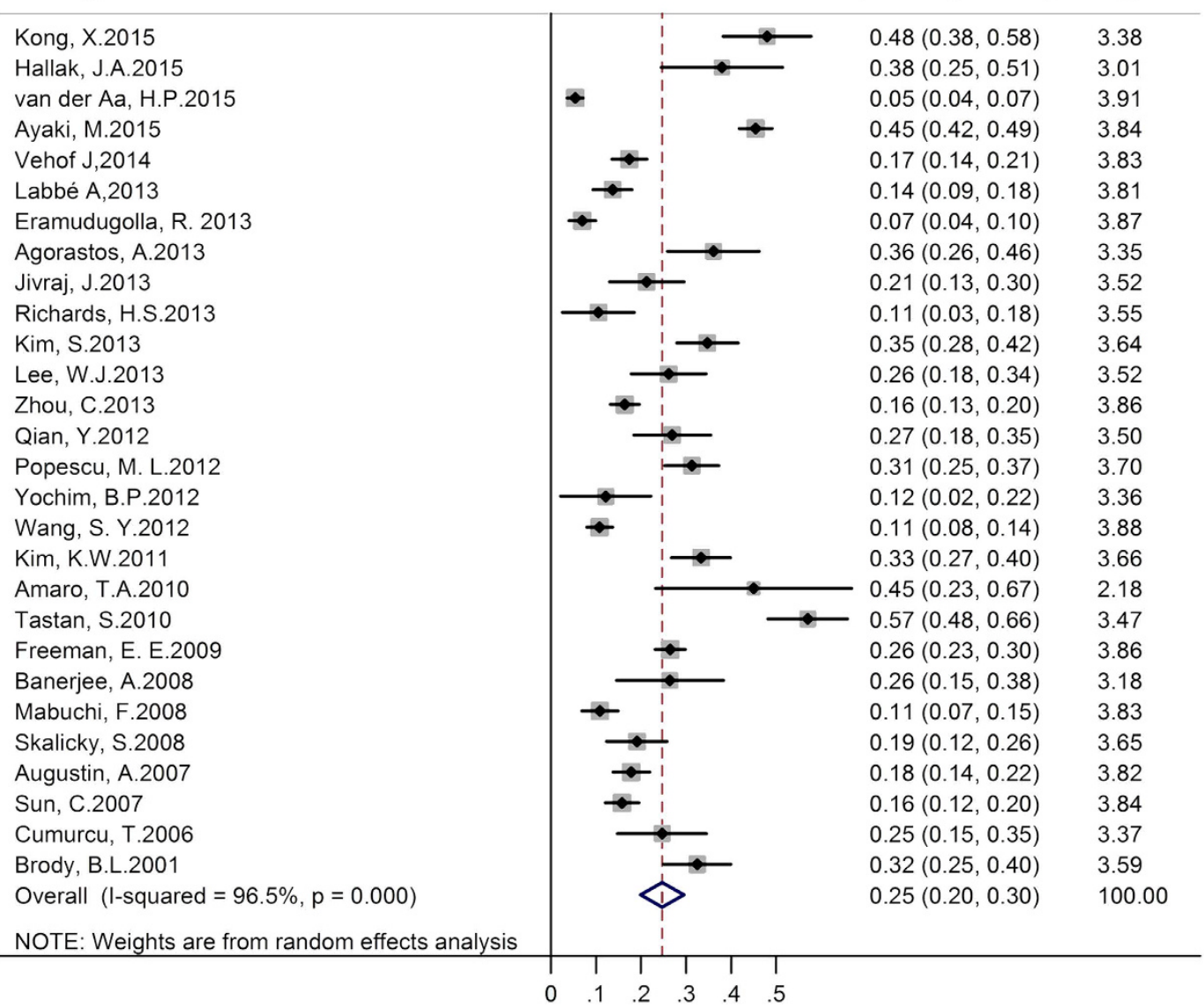

Figure 2. Forest plot of the 28 studies estimating the pooled prevalence of depression among eye disease patients.

is even more important in maintaining peaceful communications between physicians and patients. We hope the results of this study will further help develop effective strategies for preventing and treating depression among eye disease patients, meanwhile, contributing to establishing the harmonious health environment.

This study found that the prevalence of depression among eye patients was higher than that of the control group $(\mathrm{OR}=1.59,95 \% \mathrm{CI} 1.40-1.81)$. Regarding different eye disease subgroups, the highest depression prevalence was revealed for DED patients $29 \%$, followed by glaucoma, AMD and cataract patients. That indicated the prevalence of depression and depressive symptoms in DED patients was higher than that of other eye disease patients. The underlying theories may involve chronic painful symptoms of dry eye that can cause depression, the medications used to treat depression can cause or exacerbate dry eye, or the same underlying mechanism such as hormonal, metabolic or neurological imbalance that results in depression can also cause dry eye disease. Additionally, depression might affect the management and outcomes of dry eye treatment. Some reports also described DED as being closely associated with depression ${ }^{10,12}$. Aged patients are especially sensitive to negative feelings of helplessness. Some studies demonstrated that relieving eye discomfort symptoms and promoting visual rehabilitation have a positive impact on depression of ophthalmic patient $\mathrm{s}^{51,52}$. More efforts are needed to identify relevant factors inducing depression and depressive symptoms among eye disease patients and to provide appropriate prevention and treatment for mental disorders. Effective treatment of depression and screening tools are also necessary. Ophthalmologists should cooperate with psychiatrists to treat eye disease and improve mental health.

This review has a few limitations. First, the sample sizes of the included studies contributed to the observed heterogeneity in the data. Studies with small sample size might have yielded more extreme prevalence estimates, suggesting the presence of publication bias. Second, the diagnosis for depression or depressive symptoms was not uniform between studies with diverse screening instruments and cutoff scores. Additionally, the diagnosis for the eye diseases was even more complicated, contributing partially to the heterogeneity. Third, most studies involve cross-sectional or retrospective data. Also, individuals with chronic eye diseases are more likely to be screened for depression symptoms than the subjects without. Fourth, most of the included participants were aged patients and would probably suffer from systemic diseases, which may induce depression. That could be a potential confounding factor for the estimation. Therefore, a multicenter prospective study using standard diagnostic methods and screening tools on a random subset of participants would confirm this association and provide a more accurate estimate of the prevalence of depression among eye disease patients. Despite the above limitations, the findings of 


\section{a DED}

Study

Proportion $(95 \% \mathrm{Cl})$ Weight $(\%)$

Hallak.J.A. 2015

Ayaki, M. 2015

Vehof J.2014

Labbé A. 2013.

Kim, KW. 2011

Overall (I-squared $=95.1 \%, p=0.000$ )

NOTE: Weights are from random effects analysis

\section{b \\ Glaucoma}

Study

Proportion $(95 \% \mathrm{Cl}$ ) Weight $(\%$

Kong,X. 2015

Ayaki, M. 2015

Agorastos, A. 2013

Eramudugolla, R.2013

Zhou, C.2013

Popescu, M. L.2012

Wang. S. Y. 2012

Yochim,B.P. 2012

Tastan, S.2010

Mabuchi,F. 2008

Skalicky, S. 2008

Cumurcu, T. 2006

Overall (l-squared $=94.4 \%, p=0.000$ )

NOTE: Weights are from random effects analysis
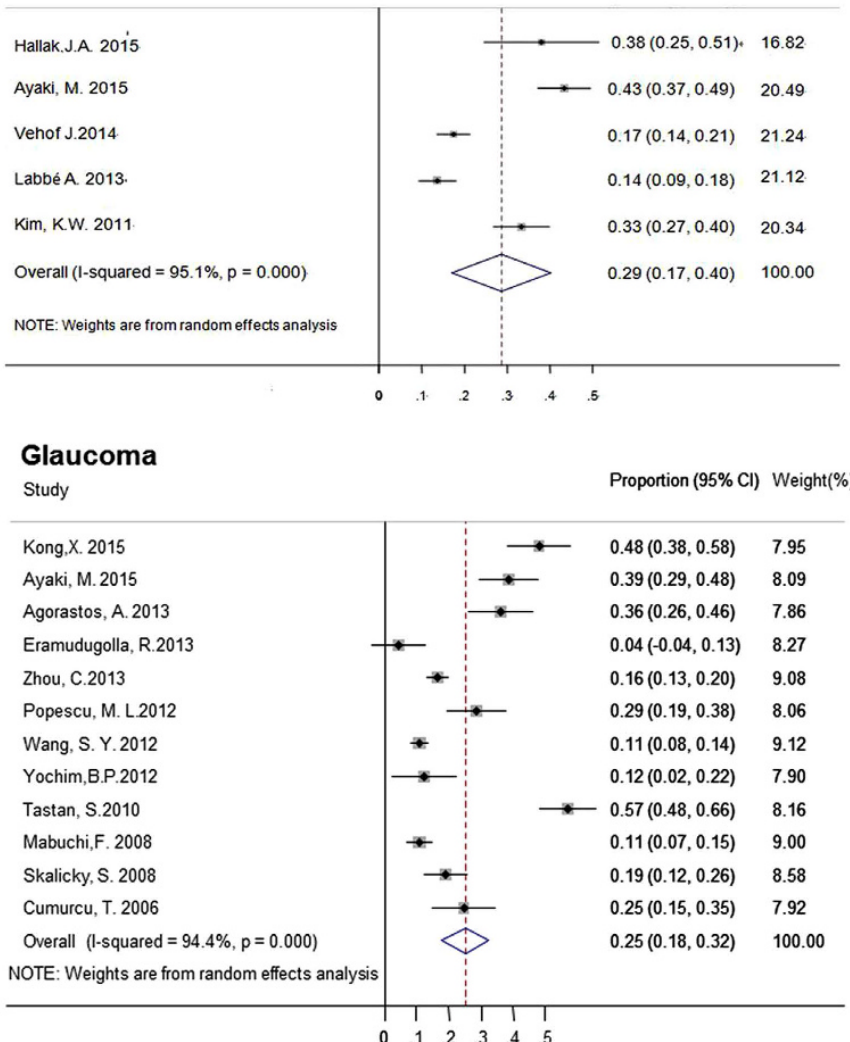

C

\section{AMD}

Study $\quad$ Proportion $(95 \% \mathrm{Cl})$ Weight $(\%)$

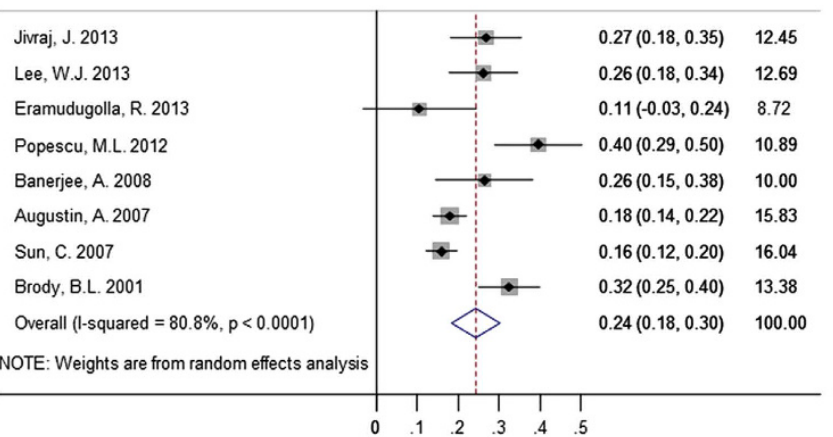

d

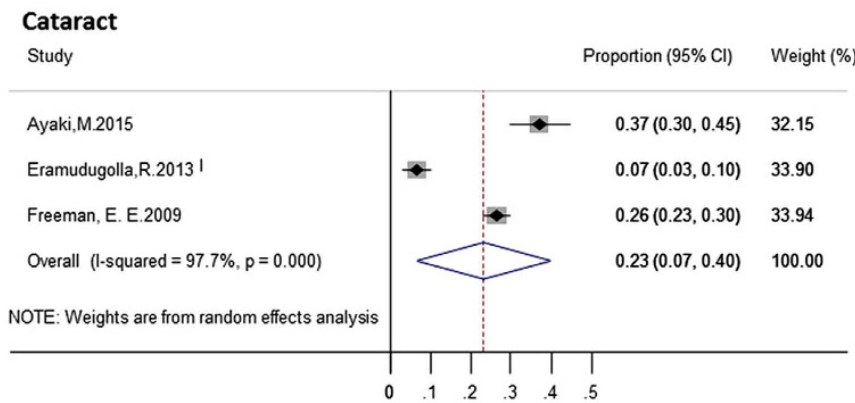

Figure 3. Forest plot of the pooled prevalence of depression in different eye disease patients. (a) Forest plot of the pooled prevalence of depression in Dry Eye Disease (DED) patients. (b) Forest plot of the pooled prevalence of depression in glaucoma patients. (c) Forest plot of the pooled prevalence of depression in Agerelated Macular Degeneration (AMD) patients. (d) Forest plot of the pooled prevalence of depression in cataract patients. 


Study
Hallak, J.A. 2015
Kong, X. 2015
Van der Aa, H.P. 2015
Eramudugolla, R. 2013
Kim, S.2013
Labbé A. 2013
Wang, S. Y. 2012
Popescu, M. L. 2012
Kim, K.W. 2011
Tastan, S. 2010
Mabuchi, F. 2008
Sun, C.2007

Figure 4. Forest plot of the 13 studies with control groups in meta-analysis.

this study suggest that the improvement of treatment of eye disease may reduce the prevalence of depression or depressive symptoms. Conversely, it might suggest that appropriate management of eye disease associated depression symptoms may improve the effectiveness of eye disease treatment and the quality of life of these patients.

In conclusion, the overall prevalence of depression among eye disease patients was $25 \%$, varying with disease categories. The prevalence of depression among eye disease patients was higher than that in healthy people. Further research is needed to identify effective strategies for preventing and treating depression among eye disease patients.

\section{Methods}

Criteria for including studies and searching methods. Descriptive studies and cross-sectional studies that reported depression or depressive symptoms among people with eye diseases were included in the systematic review. Studies were included if they were published in peer-reviewed journals, and the subjects were assessed of depression or depressive symptoms using a validated method. The diagnosis of eye diseases were based on the judgment of qualified ophthalmologists or on medical records showing a diagnosis according to the International Classification of Disease and Codes (ICD-11). The electronic databases PubMed, Medline, Embase and Cochrane Library were searched for the relevant studies published from January, 1990 to December, 2015 following the instructions of the Preferred Reporting Items for Systematic Review and Meta-Analyses (PRISMA) guidelines (Fig. 1) ${ }^{53,54}$. We also manually checked the reference lists of all retrieved studies. In our literature search, we included a combination of keywords, such as depression/depressive symptoms, prevalence/incidence, eye disease/ophthalmology, etc, in the form of title words or medical subject headings. For details, please refer to Supplementary Appendix A. Two reviewers (Y.Z. and X.W.) completed the literature search independently. In addition, these two reviewers further cross-checked the reference lists of all selected articles to identify other relevant studies. When screening discrepancies occurred, consensus was achieved after further discussion.

Data extraction and quality assessment. Data extraction from each study used a standardized form: study design, geographic location, sample size, average age of participants, disease category, diagnostic or screening method used outcome definition (cut off for specific diagnostic criteria or screening instrument), and reported prevalence of depression or depressive symptoms ${ }^{55}$. The Newcastle-Ottawa Scale (NOS) was used to assess the quality of non-randomized studies included in the systematic review and meta-analysis ${ }^{56}$, recommended by the Agency for Healthcare Research and Quality (AHRQ), available at http://www.ohri.ca/programs/ clinical_epidemiology/oxford.asp. This scale uses a star system to assess the quality of a study in three domains: selection of study groups; comparability of groups; and ascertainment of outcomes. Studies were judged to be at low risk of bias ( 3 points or more) or high risk of bias ( $<3$ points).

Data synthesis and analysis. Prevalence estimates of depression or depressive symptoms were calculated by meta-analysis based on a proportions approach for the included 28 studies and for different eye disease subgroups. Between-study heterogeneity was assessed using standard $\mathrm{x}^{2}$ tests and the $\mathrm{I}^{2}$ statistic ${ }^{57,58}$. $\mathrm{I}^{2}$ values of $50 \%$ or more were considered to indicate substantial heterogeneity, and the random-effects model was then used; 
otherwise, the fixed-effects model was used ${ }^{59}$. Thirteen studies with a control group were included in the secondary meta-analysis used the $\mathrm{I}^{2}$ statistic and the random-effect model to analyze whether there was a statistically significant difference between the subgroups with eye disease and the healthy people. A funnel plot and the Begg's test were used to investigate the publication bias between the twelve studies ${ }^{60,61}$. All analyses were performed using Stata (version 12.0, Stata Corp., College Station, TX) and R (version 3.2.1, The R Foundation, Vienna, Austria). Statistical tests were 2-sided and used a significance threshold of $p<0.05$.

\section{References}

1. Cozine, E. W. \& Wilkinson, J. M. Depression Screening, Diagnosis, and Treatment Across the Lifespan. Primary care 43, 229-243, doi: 10.1016/j.pop.2016.02.004 (2016).

2. Ustun, T. B., Ayuso-Mateos, J. L., Chatterji, S., Mathers, C. \& Murray, C. J. Global burden of depressive disorders in the year 2000. The British journal of psychiatry: the journal of mental science 184, 386-392 (2004).

3. Lopez, A. D. \& Murray, C. C. The global burden of disease, 1990-2020. Nature medicine 4, 1241-1243, doi: 10.1038/3218 (1998).

4. de Wit, L. et al. Depression and obesity: a meta-analysis of community-based studies. Psychiatry research 178, 230-235, doi: 10.1016/j.psychres.2009.04.015 (2010).

5. Morikawa, M. et al. Association between depressive symptoms and metabolic syndrome in Japanese community-dwelling older people: a cross-sectional analysis from the baseline results of the Fujiwara-kyo prospective cohort study. International journal of geriatric psychiatry 28, 1251-1259, doi: 10.1002/gps.3950 (2013).

6. Whooley, M. A. \& Wong, J. M. Depression and cardiovascular disorders. Annual review of clinical psychology 9, 327-354, doi: 10.1146/annurev-clinpsy-050212-185526 (2013).

7. Augustin, A. et al. Anxiety and depression prevalence rates in age-related macular degeneration. Investigative ophthalmology \& visual science 48, 1498-1503, doi: 10.1167/iovs.06-0761 (2007).

8. Qian, Y., Glaser, T., Esterberg, E. \& Acharya, N. R. Depression and visual functioning in patients with ocular inflammatory disease. American journal of ophthalmology 153, 370-378, e372, doi: 10.1016/j.ajo.2011.06.028 (2012).

9. Zhang, X. et al. Association between depression and functional vision loss in persons 20 years of age or older in the United States, NHANES 2005-2008. JAMA ophthalmology 131, 573-581, doi: 10.1001/jamaophthalmol.2013.2597 (2013).

10. Ayaki, M., Kawashima, M., Negishi, K. \& Tsubota, K. High prevalence of sleep and mood disorders in dry eye patients: survey of 1,000 eye clinic visitors. Neuropsychiatric disease and treatment 11, 889-894, doi: 10.2147/NDT.S81515 (2015).

11. Kong, X., Yan, M., Sun, X. \& Xiao, Z. Anxiety and Depression are More Prevalent in Primary Angle Closure Glaucoma Than in Primary Open-Angle Glaucoma. Journal of glaucoma 24, e57-63, doi: 10.1097/ijg.0000000000000025 (2015).

12. Kim, K. W. et al. Association between depression and dry eye disease in an elderly population. Investigative ophthalmology \& visual science 52, 7954-7958, doi: 10.1167/iovs.11-8050 (2011).

13. Hallak, J. A., Tibrewal, S. \& Jain, S. Depressive Symptoms in Patients With Dry Eye Disease: A Case-Control Study Using the Beck Depression Inventory. Cornea 34, 1545-1550, doi: 10.1097/ICO.0000000000000641 (2015).

14. van der Aa, H. P., Comijs, H. C., Penninx, B. W., van Rens, G. H. \& van Nispen, R. M. Major depressive and anxiety disorders in visually impaired older adults. Investigative ophthalmology \& visual science 56, 849-854, doi: 10.1167/iovs.14-15848 (2015).

15. Eramudugolla, R., Wood, J. \& Anstey, K. J. Co-morbidity of depression and anxiety in common age-related eye diseases: a population-based study of 662 adults. Frontiers in aging neuroscience 5, 56, doi: 10.3389/fnagi.2013.00056 (2013).

16. Agorastos, A. et al. Depression, anxiety, and disturbed sleep in glaucoma. The Journal of neuropsychiatry and clinical neurosciences 25, 205-213, doi: 10.1176/appi.neuropsych.12020030 (2013).

17. Jivraj, J., Jivraj, I., Tennant, M. \& Rudnisky, C. Prevalence and impact of depressive symptoms in patients with age-related macular degeneration. Canadian journal of ophthalmology. Journal canadien d'ophtalmologie 48, 269-273, doi: 10.1016/j.jcjo.2013.03.007 (2013).

18. Richards, H. S. et al. The psychological well-being and appearance concerns of patients presenting with ptosis. Eye 28, 296-302, doi: 10.1038/eye.2013.264 (2014).

19. Kim, S. et al. Mental health of people with retinitis pigmentosa. Optometry and vision science: official publication of the American Academy of Optometry 90, 488-493, doi: 10.1097/OPX.0b013e31828dee0a (2013).

20. Lee, W. J. et al. Depression of Late Age-Related Macular Degeneration Patients in Korea. Asia-Pacific journal of ophthalmology 2, 23-27, doi: 10.1097/APO.0b013e31827be8b1 (2013).

21. Zhou, C., Qian, S., Wu, P. \& Qiu, C. Anxiety and depression in Chinese patients with glaucoma: sociodemographic, clinical, and self-reported correlates. Journal of psychosomatic research 75, 75-82, doi: 10.1016/j.jpsychores.2013.03.005 (2013).

22. Popescu, M. L. et al. Explaining the relationship between three eye diseases and depressive symptoms in older adults. Investigative ophthalmology \& visual science 53, 2308-2313, doi: 10.1167/iovs.11-9330 (2012).

23. Yochim, B. P., Mueller, A. E., Kane, K. D. \& Kahook, M. Y. Prevalence of cognitive impairment, depression, and anxiety symptoms among older adults with glaucoma. Journal of glaucoma 21, 250-254, doi: 10.1097/IJG.0b013e3182071b7e (2012).

24. Wang, S. Y., Singh, K. \& Lin, S. C. Prevalence and predictors of depression among participants with glaucoma in a nationally representative population sample. American journal of ophthalmology 154, 436-444, e432, doi: 10.1016/j.ajo.2012.03.039 (2012).

25. Amaro, T. A., Yazigi, L. \& Erwenne, C. Depression and quality of life during treatment of ocular bulb removal in individuals with uveal melanoma. European journal of cancer care 19, 476-481, doi: 10.1111/j.1365-2354.2009.01073.x (2010).

26. Tastan, S., Iyigun, E., Bayer, A. \& Acikel, C. Anxiety, depression, and quality of life in Turkish patients with glaucoma. Psychological reports 106, 343-357, doi: 10.2466/PR0.106.2.343-357 (2010).

27. Freeman, E. E. et al. Cataract-related vision loss and depression in a cohort of patients awaiting cataract surgery. Canadian journal of ophthalmology. Journal canadien d'ophtalmologie 44, 171-176, doi: 10.3129/i09-001 (2009).

28. Banerjee, A., Kumar, S., Kulhara, P. \& Gupta, A. Prevalence of depression and its effect on disability in patients with age-related macular degeneration. Indian journal of ophthalmology 56, 469-474 (2008).

29. Mabuchi, F. et al. High prevalence of anxiety and depression in patients with primary open-angle glaucoma. Journal of glaucoma 17, 552-557, doi: 10.1097/IJG.0b013e31816299d4 (2008).

30. Skalicky, S. \& Goldberg, I. Depression and quality of life in patients with glaucoma: a cross-sectional analysis using the Geriatric Depression Scale-15, assessment of function related to vision, and the Glaucoma Quality of Life-15. Journal of glaucoma 17, 546-551, doi: 10.1097/IJG.0b013e318163bdd1 (2008).

31. Sun, C. et al. Depressive symptoms and age-related macular degeneration in older people: the cardiovascular health study. Ophthalmic epidemiology 14, 127-133, doi: 10.1080/09286580601186742 (2007).

32. Cumurcu, T., Cumurcu, B. E., Celikel, F. C. \& Etikan, I. Depression and anxiety in patients with pseudoexfoliative glaucoma. General hospital psychiatry 28, 509-515, doi: 10.1016/j.genhosppsych.2006.09.004 (2006).

33. Brody, B. L. et al. Depression, visual acuity, comorbidity, and disability associated with age-related macular degeneration. Ophthalmology 108, 1893-1900, discussion 1900-1891 (2001).

34. Vehof, J., Kozareva, D., Hysi, P. G. \& Hammond, C. J. Prevalence and risk factors of dry eye disease in a British female cohort. The British journal of ophthalmology 98, 1712-1717, doi: 10.1136/bjophthalmol-2014-305201 (2014). 
35. Labbe, A. et al. Dry eye disease, dry eye symptoms and depression: the Beijing Eye Study. The British journal of ophthalmology 97, 1399-1403, doi: 10.1136/bjophthalmol-2013-303838 (2013).

36. Zigmond, A. S. \& Snaith, R. P. The hospital anxiety and depression scale. Acta psychiatrica Scandinavica 67, 361-370 (1983).

37. Bjelland, I., Dahl, A. A., Haug, T. T. \& Neckelmann, D. The validity of the Hospital Anxiety and Depression Scale. An updated literature review. Journal of psychosomatic research 52, 69-77 (2002).

38. Trivedi, M. H. Tools and strategies for ongoing assessment of depression: a measurement-based approach to remission. The Journal of clinical psychiatry 70 Suppl 6, 26-31, doi: 10.4088/JCP.8133sulc.04 (2009).

39. Yesavage, J. A. et al. Development and validation of a geriatric depression screening scale: a preliminary report. Journal of psychiatric research 17, 37-49 (1982).

40. Galaria, II, Casten, R. J. \& Rovner, B. W. Development of a shorter version of the geriatric depression scale for visually impaired older patients. International psychogeriatrics/IPA 12, 435-443 (2000).

41. Beck, A. T., Ward, C. H., Mendelson, M., Mock, J. \& Erbaugh, J. An inventory for measuring depression. Archives of general psychiatry 4, 561-571 (1961).

42. Katzelnick, D. J. et al. Depression outcomes in psychiatric clinical practice: using a self-rated measure of depression severity. Psychiatric services 62, 929-935, doi: 10.1176/appi.ps.62.8.92910.1176/ps.62.8.pss6208_0929 (2011).

43. Kroenke, K., Spitzer, R. L. \& Williams, J. B. The PHQ-9: validity of a brief depression severity measure. Journal of general internal medicine 16, 606-613 (2001).

44. Goldberg, D., Bridges, K., Duncan-Jones, P. \& Grayson, D. Detecting anxiety and depression in general medical settings. Bmj 297, 897-899 (1988)

45. Biggs, J. T., Wylie, L. T. \& Ziegler, V. E. Validity of the Zung Self-rating Depression Scale. The British journal of psychiatry: the journal of mental science 132, 381-385 (1978).

46. Thurber, S., Snow, M. \& Honts, C. R. The Zung Self-Rating Depression Scale: convergent validity and diagnostic discrimination. Assessment 9, 401-405 (2002).

47. Smarr, K. L. \& Keefer, A. L. Measures of depression and depressive symptoms: Beck Depression Inventory-II (BDI-II), Center for Epidemiologic Studies Depression Scale (CES-D), Geriatric Depression Scale (GDS), Hospital Anxiety and Depression Scale (HADS), and Patient Health Questionnaire-9 (PHQ-9). Arthritis care \& research 63 Suppl 11, S454-466, doi: 10.1002/acr.20556 (2011).

48. Na, K. S., Han, K., Park, Y. G., Na, C. \& Joo, C. K. Depression, Stress, Quality of Life, and Dry Eye Disease in Korean Women: A Population-Based Study. Cornea 34, 733-738, doi: 10.1097/ICO.0000000000000464 (2015).

49. Court, H., McLean, G., Guthrie, B., Mercer, S. W. \& Smith, D. J. Visual impairment is associated with physical and mental comorbidities in older adults: a cross-sectional study. BMC medicine 12, 181, doi: 10.1186/s12916-014-0181-7 (2014).

50. Clarke, D. M. \& Currie, K. C. Depression, anxiety and their relationship with chronic diseases: a review of the epidemiology, risk and treatment evidence. The Medical journal of Australia 190, S54-60 (2009).

51. Rovner, B. W. et al. Low vision depression prevention trial in age-related macular degeneration: a randomized clinical trial. Ophthalmology 121, 2204-2211, doi: 10.1016/j.ophtha.2014.05.002 (2014).

52. Horowitz, A., Reinhardt, J. P. \& Boerner, K. The effect of rehabilitation on depression among visually disabled older adults. Aging \& mental health 9, 563-570, doi: 10.1080/13607860500193500 (2005).

53. Moher, D., Liberati, A., Tetzlaff, J., Altman, D. G. \& Group, P. Preferred reporting items for systematic reviews and meta-analyses: the PRISMA statement. International journal of surgery 8, 336-341, doi: 10.1016/j.ijsu.2010.02.007 (2010).

54. Knobloch, K., Yoon, U. \& Vogt, P. M. Preferred reporting items for systematic reviews and meta-analyses (PRISMA) statement and publication bias. Journal of cranio-maxillo-facial surgery: official publication of the European Association for Cranio-Maxillo-Facial Surgery 39, 91-92, doi: 10.1016/j.jcms.2010.11.001 (2011).

55. Kerr, L. K. \& Kerr, L. D. Jr. Screening tools for depression in primary care: the effects of culture, gender, and somatic symptoms on the detection of depression. The Western journal of medicine 175, 349-352 (2001).

56. Stang, A. Critical evaluation of the Newcastle-Ottawa scale for the assessment of the quality of nonrandomized studies in metaanalyses. European journal of epidemiology 25, 603-605, doi: 10.1007/s10654-010-9491-z (2010).

57. Takkouche, B., Khudyakov, P., Costa-Bouzas, J. \& Spiegelman, D. Confidence intervals for heterogeneity measures in meta-analysis. American journal of epidemiology 178, 993-1004, doi: 10.1093/aje/kwt060 (2013).

58. Higgins, J. P., Thompson, S. G., Deeks, J. J. \& Altman, D. G. Measuring inconsistency in meta-analyses. Bmj 327, 557-560, doi: 10.1136/bmj.327.7414.557 (2003).

59. Jones, L. et al. Prevalence and risk of violence against children with disabilities: a systematic review and meta-analysis of observational studies. Lancet 380, 899-907, doi: 10.1016/S0140-6736(12)60692-8\%/Copyright (c) 2012 Elsevier Ltd. All rights reserved (2012)

60. Sterne, J. A. \& Egger, M. Funnel plots for detecting bias in meta-analysis: guidelines on choice of axis. Journal of clinical epidemiology 54, 1046-1055 (2001).

61. Ferrer, R. L. Graphical methods for detecting bias in meta-analysis. Family medicine 30, 579-583 (1998).

\section{Acknowledgements}

This study was supported by the Key Research Plan for the National Natural Science Foundation of China in Cultivation Project (No. 91546101), the Pear River Scholar Program of Guangdong Province (Haotian Lin), the Outstanding Young Teacher Cultivation Projects in Guangdong Province (No. YQ2015006), the Guangdong Provincial Natural Science Foundation for Distinguished Young Scholars of China (No. 2014A030306030), the Youth Science and Technology Innovation Talents Funds in a Special Support Plan for High Level Talents in Guangdong Province (No. 2014TQ01R573) and the Young Teacher Top-Support project of Sun Yat-sen University (No. 2015ykzd11). The sponsor or funding organization had no role in the design or conduct of this research.

\section{Author Contributions}

Y.Z. and X.W. designed the study, wrote the manuscript and approved the final version. Y.Z. and X.W. collected and analyzed data. Y.Z. and X.W. wrote the manuscript. H.L. critically reviewed and revised the manuscript. H.L. and X.L. contributed to the funding of the researches, coordinated researches and oversaw the project. All authors reviewed and finally approved the manuscript.

\section{Additional Information}

Supplementary information accompanies this paper at http://www.nature.com/srep

Competing Interests: The authors declare no competing financial interests.

How to cite this article: Zheng, Y. et al. The Prevalence of Depression and Depressive Symptoms among Eye Disease Patients: A Systematic Review and Meta-analysis. Sci. Rep. 7, 46453; doi: 10.1038/srep46453 (2017). 
Publisher's note: Springer Nature remains neutral with regard to jurisdictional claims in published maps and institutional affiliations.

(c) (i) This work is licensed under a Creative Commons Attribution 4.0 International License. The images or other third party material in this article are included in the article's Creative Commons license, unless indicated otherwise in the credit line; if the material is not included under the Creative Commons license, users will need to obtain permission from the license holder to reproduce the material. To view a copy of this license, visit http://creativecommons.org/licenses/by/4.0/

(C) The Author(s) 2017 